\title{
Survival of Teliospores of Tilletia indica in Arizona Field Soils
}

\author{
M. R. Bonde and S. E. Nester, USDA-ARS, Foreign Disease-Weed Science Research Unit, Fort Detrick, MD \\ 21702-5023; M. W. Olsen, Department of Plant Pathology, University of Arizona, P.O. Box 210036, Tucson 85721- \\ 0036; and D. K. Berner, USDA-ARS, Foreign Disease-Weed Science Research Unit, Fort Detrick, MD 21702-5023
}

\begin{abstract}
Bonde, M. R., Nester, S. E., Olsen, M. W., and Berner, D. K. 2004. Survival of teliospores of Tilletia indica in Arizona field soils. Plant Dis. 88:804-810.

The survival of teliospores of the Karnal bunt of wheat pathogen, Tilletia indica, was determined in field plots in Tucson, AZ. Two methods were used to test viability during a 48-month period in which $21-\mu \mathrm{m}$-pore-size polyester mesh bags of teliospore-infested soil were buried in irrigated and nonirrigated field plots at two sites. One method determined the total number of viable teliospores in a soil sample, regardless of whether or not they could be extracted from the soil using a sucrose centrifugation technique. The total number of viable teliospores declined over time in both irrigated and nonirrigated field plots and in the same soils in the laboratory. Based on nonlinear regressions, total number of viable teliospores decreased from $55.7 \%$ at time zero to 9.7 and $6.7 \%$ for nonirrigated and irrigated field soils, respectively, in 48 months. Total number of viable teliospores in soil in the laboratory decreased from 55.7 to $34.0 \%$ after 48 months. The second method determined germination percentages of teliospores extracted from the soil samples by means of a sucrose centrifugation technique. Based on linear regressions of transformed data, germination of teliospores extracted from irrigated and nonirrigated field soils, and control (laboratory) soil, significantly decreased over time. The rate of decrease in germination was significantly greater for teliospores from irrigated field plots than from nonirrigated plots and the laboratory soil. At time zero, $55.7 \%$ of teliospores germinated, and by 48 months, average germination of teliospores extracted from soil in nonirrigated plots had decreased to $13.6 \%$ compared with $4.4 \%$ in irrigated plots and $36.8 \%$ for teliospores in the laboratory control. Regression over time of total number of viable teliospores accounted for more of the overall variability than did regression over time of germination percentages of extracted teliospores. Neither field site nor soil depth had any effect on total number of viable teliospores or on teliospore germination percentages.
\end{abstract}

Additional keywords: Neovossia indica, partial bunt, teliospore enumeration, teliospore extraction

When wheat seeds infected with Tilletia indica $\mathrm{M}$. Mitra (=Neovossia indica (M. Mitra) Mundk.) were discovered in the southwestern United States in 1996, a massive field-to-field pre- and postharvest disease survey was conducted (4). Later that year, a nationwide Karnal bunt survey of harvested grain was conducted to determine how extensively the disease had spread (4).

Karnal bunt reduces wheat yields and causes a fishy, unpalatable odor and taste

Corresponding author: M. R. Bonde

E-mail: mbonde@fdwsr.ars.usda.gov

The use of trade, firm, or corporation names in this publication is for the information and convenience of the reader. Such use does not constitute an official endorsement or approval by the United States Department of Agriculture or the Agricultural Research Service of any product or service to the exclusion of others that may be suitable.

Accepted for publication 24 March 2004.

Publication no. D-2004-0520-01R

This article is in the public domain and not copyrightable. It may be freely reprinted with customary crediting of the source. The American Phytopathological Society, 2004 in wheat flour, reducing its quality (20). Since Karnal bunt is the subject of strict quarantines by several wheat-importing countries, $T$. indica can profoundly affect the international trade of commercial wheat grain and movement of germ plasm (4). The primary impact of the disease is the effect of quarantines on trade, since yield and quality losses are generally minor $(5,9)$.

Teliospores of $T$. indica are very resistant to adverse environmental conditions and have been reported to survive in contaminated soil for 2 to 5 years $(7,12-$ 14,16). The pathogen is seedborne but not transmitted directly from seed to plant $(10,13)$. Teliospores at or just under the soil surface germinate to produce sporidia that spread onto the surface of glumes enclosing developing wheat kernels (4). If moist weather occurs during the 2- to 3week period when plants are susceptible to infection, germinating sporidia penetrate stomata of the glumes and grow to the base of the glumes and up into the developing kernels (10). Here, new teliospores are produced that are eventually redeposited onto the surface of the soil. Teliospores, being the only means of survival and the main means of pathogen spread, play a vital role in the perpetuation and spread of the disease. For that reason, they are of particular interest to plant disease regulatory officials.

When Karnal bunt was first discovered in the United States, information was desired on longevity of teliospores of $T$. indica in Arizona field soil. In April 1998, we initiated a teliospore longevity study in Arizona field plots. Although the study has not been concluded, results of that study to date are reported here.

The research was conducted with the permission of the U.S. and Arizona Departments of Agriculture. All research with noncontained teliospores, including preparation of bags of teliospore-infested soil and teliospore viability testing, was done in the USDA-ARS plant disease containment facility at Fort Detrick, MD.

\section{MATERIALS AND METHODS}

Bag preparation. Bags to contain $T$. indica teliospore-infested soil were made from two $7.6 \times 7.6 \mathrm{~cm}$ pieces of $21-\mu \mathrm{m}$ pore-size polyester mesh (Sefar America Inc., Kansas City, MO) glued together at three edges with silicone glue (GE Silicon II Household Glue and Seal, Waterford, NY). The fourth side was sealed with silicone glue after addition of the infested soil. All four sides then were stitched with a sewing machine.

Soil preparation. Soil to be infested with teliospores came from the top $20 \mathrm{~cm}$ of the field plots in which the study was to be conducted. It was air-dried, sieved through a 2-mm-pore-size sieve to eliminate large rocks, soil clumps, and debris, and then shipped to Frederick, MD. A subsample was analyzed for physical and chemical characteristics at the Inter $\mathrm{Ag}$ Services Laboratories, Phoenix, AZ.

Teliospore preparation and addition to soil. Teliospores were scraped from infected seeds obtained in 1996 from Sonora, Mexico, and suspended in Tween 20 water (1 drop Tween/100 ml), passed through a 53- $\mu \mathrm{m}$-pore-diameter nylon screen, and poured onto a 21- $\mu \mathrm{m}$-porediameter polyester screen to eliminate teliospores smaller than $21 \mu \mathrm{m}$ diameter. Teliospores collected on the second screen were suspended in $50 \mathrm{ml}$ of sterile distilled water by gentle stirring with a magnetic stir bar, and a $48-\mu$ aliquot containing $1 \times$ $10^{4}$ teliospores was added to each bag containing $3 \mathrm{~g}$ of soil. The bags were glued shut as described, allowed to cure, stitched with a sewing machine, and shipped to 
Tucson. Bags of air-dried teliosporeinfested soil also were maintained in sealed plastic bags in the laboratory at room temperature to serve as controls.

Field plots. The study was conducted in two $7 \times 12 \mathrm{~m}$ field sites at the University of Arizona Campus Agricultural Center in Tucson. Each site was divided into two plots. One plot was rain fed only, and the other plot received $5.0 \mathrm{~cm}$ of flood irrigation twice monthly from 1 May to 31 October and once monthly from 1 November to 30 April. The bags containing infested soil were placed at 2-, 10-, and $20-\mathrm{cm}$ depths in holes spaced approximately $1 \mathrm{~m}$ apart. In each of the four plots, 72 holes were divided into six blocks of 12 holes to allow for randomized sampling of six replications at each of 12 sampling times over the length of the experiment. A piece of polyvinyl chloride pipe was inserted into each hole near bags to mark locations. At each sampling date, one set of bags (2-, $10-$, and $20-\mathrm{cm}$ depths) was taken out of each of the six blocks in each plot according to a randomly generated set of numbers representing each of 12 sampling times.

Bags were buried on 15 April 1998 and recovered after 3 and 6 months and then at 6-month intervals up to 48 months. Immediately upon recovery, bags were doubly sealed in plastic bags and sent to Frederick, MD, for teliospore viability tests.

After 36 and 42 months, soil moisture was determined gravimetrically for each depth in each plot using standard methods (6). Samples were taken from all replications at each depth in all plots at the times the bags were retrieved. The samples were stored in sealed soil tins for transport to the laboratory. Moist samples were weighed, dried at $105^{\circ} \mathrm{C}$ for $48 \mathrm{~h}$, and then reweighed. Moisture content was calculated as a percentage of the mass of dry soils by the equation: $100 \times$ (wet weight - dry weight/dry weight). Soil temperatures were taken at 2- and $20-\mathrm{cm}$ depths at one location in each plot throughout the study using Hobo Data Loggers (Onset Computer Corp., Pocasset, MA). Air temperature and rainfall were recorded continuously throughout the study at the University of Arizona AZMET weather station located about $200 \mathrm{~m}$ from the plots.

Extraction of teliospores from soil samples. Upon arrival of the bags in Frederick, the glued edges were trimmed off and discarded. Bags were opened, and the $3-\mathrm{g}$ soil sample was placed in a $250-\mathrm{ml}$ beaker along with the cut pieces of the bag. Sufficient distilled water was added to cover the soil, and it was allowed to sit overnight at room temperature. The next day, $100 \mathrm{ml}$ of distilled water containing 1 drop Tween 20/100 $\mathrm{ml}$ was added to the soil in each beaker and stirred for $3 \mathrm{~min}$ with a magnetic stirrer. The suspension was filtered through a 53- $\mu \mathrm{m}$-pore-size nylon screen, and the filter was rinsed with a fine stream of water until 1,000 ml was collected. The suspension then was poured through a $20-\mu \mathrm{m}$-pore-size nylon screen to recover the teliospores, which then were washed from the screen into a $50-\mathrm{ml}$ centrifuge tube and centrifuged at 1,200 $\times g$ for $3 \mathrm{~min}$. The liquid was decanted and the pellet suspended in $35 \mathrm{ml}$ of $80 \%$ sucrose, centrifuged at $200 \times g$ for $40 \mathrm{~s}$, and decanted onto a $20-\mu \mathrm{m}$ screen. The residual pellet was extracted three more times. The residue containing extracted teliospores collected on the screen was washed by means of a fine stream of water, transferred into a 15-ml centrifuge tube, brought to $14 \mathrm{ml}$ with distilled water, and incubated at $20^{\circ} \mathrm{C}$ overnight.

Preparation of acidic electrolyzed water. Extracted teliospores were sterilized using acidic electrolyzed water generated by electrolysis in a Super Oxseed Laboratory JED 020 apparatus (Advanced $\mathrm{H}_{2} \mathrm{O}$, Alameda, CA) (3). During generation, an electric current was passed through a dilute aqueous solution of sodium chloride, and acidic electrolyzed water was generated in the anode compartment and alkaline water in the cathode compartment. Acidic electrolyzed water was prepared fresh each day of an experiment according to the manufacturer's directions. In brief, sodium chloride $(0.70 \mathrm{~g})$ was dissolved in 4 liters of tap water, 2 liters each was poured into the anode and cathode compartments, and electrolysis was allowed to proceed for 15 min. The $\mathrm{pH}$ of the acidic electrolyzed water was 2.5 to 2.8 , oxidation/reduction potential $1,130 \mathrm{mV}$, and free chlorine content, determined by spectrophotometric analysis at $528 \mathrm{~nm}$ using $N, N$-diethyl- $p$ phenylenediamine (21), 15 ppm.

Recovery rates and extraction efficiency. Five thousand teliospores were added to each of three bags, each containing 3-g of air-dried soil, and samples were extracted using the method above. Following extraction, the number of teliospores recovered per soil sample was enumerated by means of a Howard Mold Counting Chamber (Hausser Scientific Co., Horsham, PA) using the method described by the manufacturer. The experiment was repeated with $1 \times 10^{4}$ teliospores per 3 -g soil sample. During the course of the 48month study, the number of teliospores recovered was determined for each bag of infested soil buried in the field plots and for infested soil maintained in the laboratory.

In a separate experiment, the extraction procedure was evaluated by determining teliospore losses in the fractions that normally were discarded. Three 30-month-old field samples and three 3-g samples of Arizona soil freshly seeded with 10,000 teliospores (equivalent to zero time in the field plots) were extracted and plated as usual. In addition, portions of the $>53-\mu \mathrm{m}$ fraction from the first wet screening, the $<20-\mu \mathrm{m}$ fraction from the second wet screening, and the $<20-\mu \mathrm{m}$ fraction created during the sucrose extraction were treated with acidic electrolyzed water and assayed for viable teliospores. Process losses for freshly infested samples were calculated by comparing total number viable teliospores with the theoretical number of viable teliospores calculated from percent germination results.

Viability of teliospores extracted from soil. At each sampling date, soil from three replications for each plot at each depth was tested immediately upon arriving in Frederick, MD. Three additional replications for each plot at each depth were retained for later testing, if required. In addition, identical infested soil that had been airdried and maintained in the laboratory in polyester mesh bags within closed plastic bags at room temperature was tested. Soil was removed from the bags and teliospores extracted by a modification of the technique of Babadoost and Mathre (1), as described above. Soil from the second set of replications for 6-, 12-, and 42-month samples was tested for germinability 6 months after the first sets, respectively, in order to detect possible teliospore dormancy at the time of the first tests.

To test for viability, the extracted debris (containing teliospores) was resuspended in $14 \mathrm{ml}$ of water, incubated overnight at $20^{\circ} \mathrm{C}$, centrifuged at $1,200 \times g$ for $3 \mathrm{~min}$, and the supernatant discarded. The pellet was resuspended in $14 \mathrm{ml}$ of acidic electrolyzed water (3) and gently rocked for 30 min on a Speci Mix (Barnstead/ Thermolyne, Dubuque, IA). The suspension was centrifuged at $1,200 \times g$ for 3 min, supernatant removed, and pellet resuspended in $14 \mathrm{ml}$ of sterile distilled water. The resulting suspension was centrifuged at $1,200 \times g$ for $3 \mathrm{~min}$ and the supernatant discarded. The final pellet was resuspended in $2 \mathrm{ml}$ of sterile $0.1 \%$ water agar (to help keep teliospores in suspension), and the number of teliospores per $\mathrm{ml}$ was enumerated by means of four replicate counts in a Howard Mold Counting Chamber according to directions given by the manufacturer. An aliquot calculated to contain 100 teliospores was placed on $2 \%$ water agar containing $100 \mathrm{mg}$ each of streptomycin sulfate and ampicillin sodium salt per liter in each of six petri dishes. The volume of liquid per petri dish was brought to $200 \mu \mathrm{l}$ and spread over the surface of the solid medium. Petri dishes were incubated at $20^{\circ} \mathrm{C}, 12-\mathrm{h}$ day length (cool-white fluorescent light), and examined at $\times 10$ to $\times 100$ magnification after 11 days to determine numbers of $T$. indica colonies growing per dish.

Determination of total number of viable teliospores in a soil sample. Following extraction of teliospores from the respective soil samples, the residual soil pellets (containing teliospores not able to be extracted from the soil samples) were each suspended in $35 \mathrm{ml}$ of $0.1 \%$ agar and 
a 1-ml aliquot transferred to a 20 - $\mu$ m-poresize screen, rinsed, and all material retained by the screen placed in a 15-ml centrifuge tube. This material was treated with acidic electrolyzed water as described for the extract above, suspended in $1.2 \mathrm{ml}$ of $0.1 \%$ sterile water agar, and divided onto six petri dishes. The dishes were incubated as above and examined microscopically after 11 days to determine numbers of colony forming units of T. indica.

The number of viable teliospores in a sample extract was calculated by dividing the 2-ml extract volume by the volume estimated to contain 100 teliospores and multiplying this figure by the average number of colonies per each of the six extract assay petri dishes for the sample. The number of viable teliospores in the residual pellet was estimated by totaling the number of colonies on all six pelletassay dishes and multiplying by 35 , since $1 / 35$ of the residual pellet had been plated. The number of viable teliospores in the extract was added to the number estimated to be present in the residual pellet to provide an estimate of the total number of viable teliospores in a soil sample.

Statistical analyses. Teliospore germination percentages were transformed by arcsine square root prior to statistical analysis. These data then were subjected to analysis of covariance with the GLM procedure of SAS (Statistical Analysis System, SAS Institute, Cary, NC) to test for significance of field sites, laboratory and field plots, soil depths, the interaction among these effects, and the covariates of sampling times within plots. The interaction term for field site by plot was used to test differences between sites and plots. The model error term was used to test all other effects. A subsequent analysis of covariance was done with the GLM procedure using pooled data from field sites and soil depths for each field plot, with sampling time within plots as covariates. Linear regression equations for transformed teliospore germination within each plot were formed from the latter analysis. Slope estimates for each plot were statistically compared using linear contrasts. The regression equations along with least square means and standard errors for each plot at each sampling time were plotted. Regression analysis for each plot was done with the GLM procedure to generate $R^{2}$ values for each plot. In the same manner, quadratic and nonlinear regression analyses were done on total numbers of viable teliospores.

Teliospore appearance. During the course of the study, representative teliospores that were extracted from soil samples were mounted in Shears solution (11) and photographed digitally using an Optronics 1-CCD Digital Video Camera on an Olympus BX 41 compound microscope. These photographs were later examined to determine changes in appearance during incubation in irrigated, nonirrigated, and laboratory soil samples.

\section{RESULTS}

Plot environment. Soil for site 1 was a clay loam, $36 \%$ sand, $36 \%$ silt, and $28 \%$ clay. Soil of site 2 was a sandy clay loam with $52 \%$ sand, $25 \%$ silt, and $23 \%$ clay. Soil $\mathrm{pH}$ was 8.4 and 8.3 at site 1 and site 2 , respectively.

The soil moisture data verified that moisture levels in irrigated plots were significantly higher than in nonirrigated plots on 15 October 2001 for both site 1 and site $2(P<0.05)$. For site 1 , the moisture levels on 15 October averaged among the three depths were 9.5 and $20.1 \%$ for nonirrigated and irrigated plots, respectively. For site 2, the moisture levels on 15 October for nonirrigated and irrigated plots averaged 4.3 and $14.8 \%$, respectively.

On 16 April 2001, the moisture differences between irrigated (17.7\%) and nonirrigated $(13.9 \%)$ plots were small but significant $(P<0.05)$. The nonirrigated plots were wetter than on 15 October. Soil of irrigated plots always had higher moisture at 10 and $20 \mathrm{~cm}$ than at $2 \mathrm{~cm}$ depth.

Only air temperature data were collected in 1998. Beginning in 1999, both air and soil temperature data were collected. Average daily air and soil temperatures peaked from 14 June to 4 July 1999, 29 May to 18 June 2000, and 28 May to 9 September 2001. The longest period of hot weather was in the summer of 2001. Average daily soil temperatures were generally 1 to $4^{\circ} \mathrm{C}$ higher at $2 \mathrm{~cm}$ than at $20 \mathrm{~cm}$, and 3 to $6^{\circ} \mathrm{C}$ higher in nonirrigated versus irrigated plots.

Extreme fluctuations in soil temperatures sometimes occurred during spring and summer months and were greater at 2 $\mathrm{cm}$ than $20 \mathrm{~cm}$. For example, in the nonirrigated plots from 4 to 21 June 2001, the soil temperature at a depth of $2 \mathrm{~cm}$ usually peaked at 48 to $54^{\circ} \mathrm{C}$ during the day and dipped to 18 to $29^{\circ} \mathrm{C}$ at night. At $20 \mathrm{~cm}$ depth, temperatures peaked at 25 to $29^{\circ} \mathrm{C}$ during the day and dipped to 23 to $28^{\circ} \mathrm{C}$ during the night.

During winter months, the average weekly air temperature dropped to 5 to $9^{\circ} \mathrm{C}$ on a few occasions during the 4-year period. Soil temperatures at both 2 and 20 $\mathrm{cm}$ depths were 2 to $4^{\circ} \mathrm{C}$ higher than air temperature. Periods of freezing were not experienced, and average weekly soil temperatures never went below $6^{\circ} \mathrm{C}$.

Teliospore extraction efficiency. A mean of $65 \%$ (range 57 to $74 \%$ ) of fresh teliospores were recovered when added to soil and extracted immediately (Fig. 1A). When the experiment was repeated, an average of $61 \%$ was recovered.

Three months after burying bags of infested soil in field plots, the number of teliospores able to be extracted dropped to an average of approximately $13 \%$ (irrigated $=10 \%$, nonirrigated $=15 \%$ ) of the total added and remained relatively consistent with an average of $23 \%$ (irrigated $26 \%$, nonirrigated $21 \%$ ) for the remainder of the 42 months of the experiment (Fig. 1). Extraction percentages from irrigated and nonirrigated plots did not decrease significantly after 3 months $(P<0.05)$. The numbers of teliospores extracted from laboratory soil did not decrease $(P<0.05)$ during the entire experiment and averaged $59 \%$ of those originally placed in the soil. The numbers of teliospores able to be extracted from the laboratory soil, irrigated, and nonirrigated plots were significantly different from each other, although the latter two differed only slightly. More teliospores were extracted from irrigated plots than from nonirrigated plots.

An average of $59 \%$ (range 0 to $98 \%$ ) of the total number of viable teliospores in 24-, 36-, and 48-month-old field samples was not extracted by $80 \%$ sucrose centrifugation and remained in the pellets. In contrast, only $20 \%$ (range 6 to $40 \%$ ) of the total number of viable teliospores in control soil samples kept in the laboratory was not extracted.

Examination of all fractions normally discarded during extraction showed teliospore losses were small. Only three viable teliospores passed through the $20-\mu \mathrm{m}$ screens, one during the wet screening and two after the sucrose extraction. These would not have been included in teliospore counts and thereby reduced the total number of viable teliospores by an average of 13 teliospores per sample. Teliospores were not lost when the large debris trapped on the 53- $\mu \mathrm{m}$ screens was discarded.

In a separate experiment, total teliospore loss from eight soil samples seeded with 1 $\times 10^{4}$ fresh (nonweathered) teliospores was as high as 4,424 and averaged 1,217 viable teliospores per sample. This equaled 20 to $25 \%$ of the total number of viable teliospores, based on colony counts when soil extracts and residual soil pellets were spread on germination medium.

Dormancy results. Teliospores extracted immediately from 12-month soil samples germinated $5.7 \%$ higher than teliospores from duplicate 12-month soil samples that were held for 6 months in the laboratory before spreading on medium. Germination results throughout the study gave no indication of dormancy.

Germinability of teliospores extracted from soil samples. Statistical analyses showed no significant differences in germination between sites or among soil depths. Therefore, these data were pooled for subsequent analyses. After 48 months in field plots, the average percent teliospore germination had decreased gradually to $36.8 \%$ for soil in the laboratory, $13.6 \%$ for nonirrigated plots, and $4.4 \%$ for irrigated plots (Fig. 1B). Analysis of covariance, using sampling times within plots as covariates, showed significant decreases in teliospore germination over time for all 
plots (Table 1). The individual regressions accounted for 38 to $54 \%$ of the overall variation. The rate of decrease in germination was statistically the same for teliospores in the laboratory soil and in nonirrigated field plots, but was significantly faster for irrigated plots. With the exception of initial sampling time, single degreeof-freedom contrasts showed that teliospore germination within each treatment (irrigated, nonirrigated, or laboratory control) was significantly different from both other treatments at each sampling time.

Although raw percentages of teliospore germination at sampling time zero were the same for both plots and teliospores in laboratory soil, regression analysis produced different estimates of initial germination percentages. The least squares mean estimate of initial germination in irrigated plots was significantly different than estimates for germination in both nonirrigated plots and laboratory soil (Fig. 1B). With the exception of initial sampling time, least square mean estimates and standard errors showed that teliospore germination within each treatment, including laboratory soil, was significantly different from both other treatments at each sampling time.

Total number of viable teliospores in a soil sample. Statistical analyses of the total number of viable teliospores demonstrated that there were no differences between sites, or among depths, within irrigated plots or nonirrigated plots. Quadratic regressions for each treatment accounted for 55 to $82 \%$ of the overall variation (Table 2). In both irrigated and nonirrigated plots, there was a rapid and highly significant decrease in total number of viable teliospores over time (Fig. 2). The rate of decrease in total number of viable teliospores in the laboratory soil was not significant (Table 2). Rates of decrease in total number of viable teliospores were statistically the same for irrigated and nonirrigated plots, and single degree-offreedom contrasts showed no differences in total number of viable teliospores between these plots at any sampling time. At 48 months, in nonirrigated plots an average of $970(9.7 \%)$ of the teliospores were still viable, and in irrigated plots, an average of $670(6.7 \%)$ of the teliospores were viable (Fig. 2). Control teliospores maintained 48 months free of soil in the laboratory and control teliospores maintained in soil in the laboratory had average numbers of viable teliospores of 4,697 (47.0\%) and 3,400 (34.0\%), respectively, down from $5,570(55.7 \%)$ at the beginning of the study 48 months earlier. Nonlinear regressions of total number of viable teliospores in irrigated and nonirrigated field plots and soil in the laboratory over five sampling times and linear transformations of the regression equations are presented in Figure 2.

Physical appearance of teliospores recovered from soil. Microscopic examina- tion of teliospores extracted from soil in the field revealed obvious changes in appearance by 3 months. At 3 months, the sheath surrounding the outer wall appeared degraded. As time progressed, changes became more pronounced (Fig. 3). The outer wall of the teliospore usually appeared ragged and much lighter in color than teliospores prior to placing in soil. Little or no change in appearance occurred
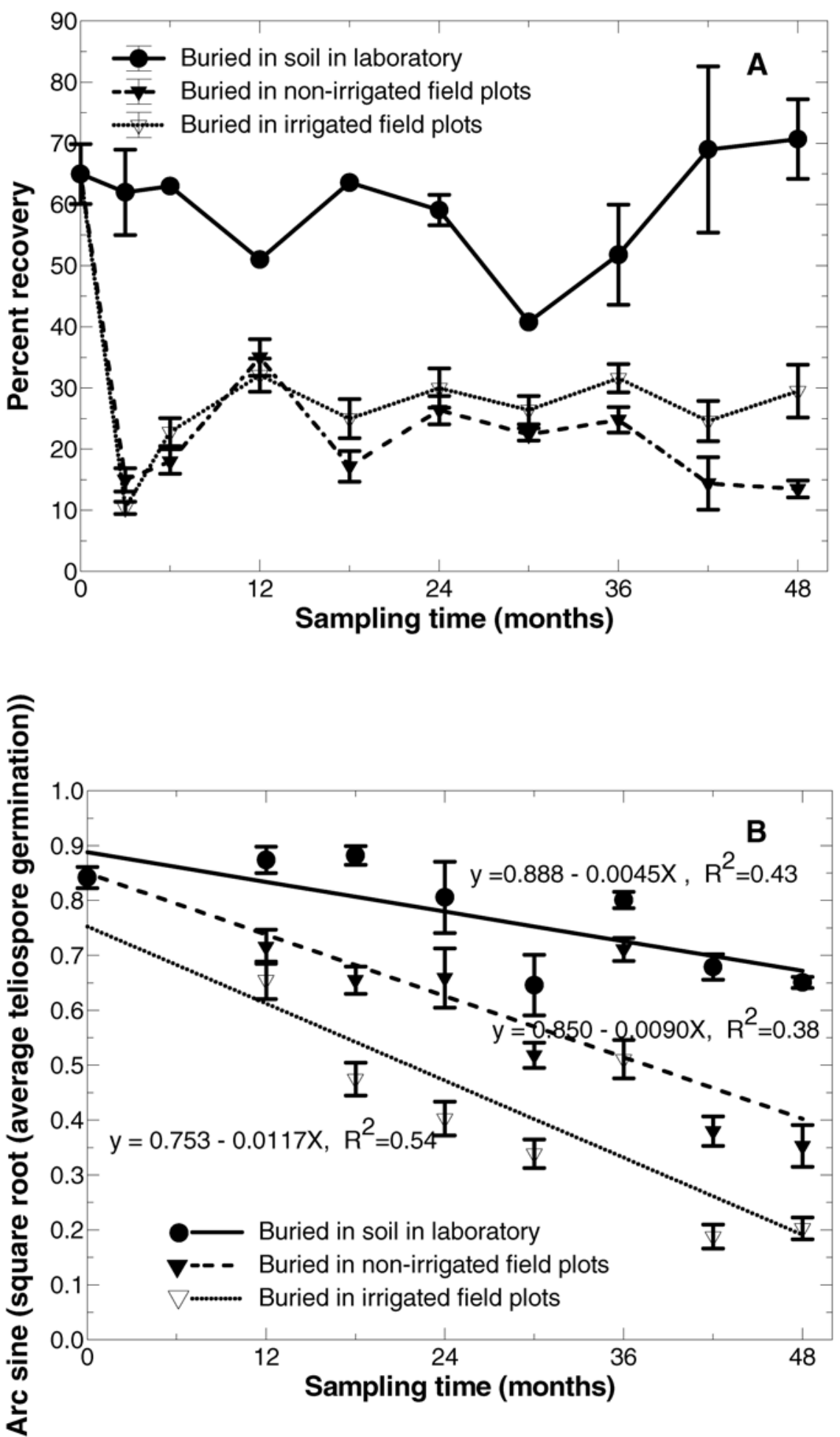

Fig. 1. Percentages of the teliospores originally added to soil that were recovered after being buried in field plots or kept in the laboratory for 0 to 48 months, and percent teliospore germination of recovered teliospores. A, Percentages of the original $1 \times 10^{4}$ teliospores added to 3-g soil samples that were recovered from irrigated and nonirrigated field samples, or samples maintained in the laboratory. B, Linear regressions of transformed germination percentages of teliospores extracted from 3-g soil samples maintained in 21- $\mu \mathrm{m}$-pore-size polyester mesh bags buried in irrigated or nonirrigated field plots, or maintained dry in sealed plastic bags at room temperature in the laboratory as a control. Standard errors of the means are indicated for both $\mathbf{A}$ and $\mathbf{B}$. 
for teliospores maintained in soil in the laboratory (Fig. 3).

\section{DISCUSSION}

The enumeration of viable teliospores in soil samples presented two challenges that had to be overcome during the course of this study in order to be certain of the validity of conclusions. The first challenge was to eliminate the necessity of making $T$. indica teliospore identifications on the surface of agar, where it was often difficult to differentiate nongerminated teliospores from soil particles as the spores deteriorated. This was accomplished by microscopically enumerating teliospores in soil extracts using a Howard Mold Counting Chamber. Then, an aliquot containing 100 teliospores was spread over the water agar surface of each of six petri dishes. After 11 days, the number of $T$. indica colonies was determined; the average number of colonies per dish was a good estimate of the germinability of the teliospores in the soil extract. For example, an average of 50 colonies per each of six dishes equaled a germination of $50 \%$.

The second challenge to overcome was the combined problem of low teliospore recovery and excessive variation in numbers of teliospores extracted from replicate soil samples. The soil pellet assay we developed to meet the challenge was ex- tremely important to the ultimate success of the study. It allowed accurate and valid determinations of numbers of viable teliospores in soil regardless of inconsistent and/or low teliospore extraction efficiency. By comparing total numbers of viable teliospores over time, it was possible to determine the rate of decline in viability in a population. Nongerminated teliospores did not have to be distinguished from soil particles of similar size. Data were dependent on counting $T$. indica colonies, easily recognized by their characteristic growth, color, and accompanying sporidia. The optimum time for examination was determined to be 11 days after spreading teliospore suspensions on medium because all viable teliospores had germinated. Furthermore, secondary colonies from sporidia had not developed, which could artificially inflate teliospore survival numbers.

Another study suggested that a large reduction in numbers of teliospores extracted from infested soil after 1 year in the field was caused by teliospore degradation (2). Calculations were based on a single extraction efficiency, equal to $80 \%$, determined at the beginning of the study using nonweathered teliospores. We demonstrated here that much of the reduction in teliospore numbers in this study was caused by a reduced extraction efficiency as early as

Table 1. Estimates and contrasts of slopes, based on arcsine square root transformation of raw data, for teliospore germination in different plots over time

\begin{tabular}{lcccrc}
\hline & $\begin{array}{c}\text { Slope }^{\mathbf{a}} \\
\text { estimates }\end{array}$ & $\begin{array}{c}\text { Standard } \\
\text { error }\end{array}$ & $\boldsymbol{t}$ value & $\boldsymbol{P}>|\mathbf{t}|$ & $\begin{array}{c}\text { Full model }^{\mathbf{b}} \\
\boldsymbol{R}^{\mathbf{2}}\end{array}$ \\
\hline Laboratory (L) & -0.005 & 0.002 & -2.68 & 0.01 & 0.43 \\
Nonirrigated (N) & -0.009 & 0.001 & -9.65 & $<0.01$ & 0.38 \\
Irrigated (I) & -0.012 & 0.001 & -12.25 & $<0.01$ & 0.54 \\
Contrast & df & Contrast SS & $F$ value & $P>F$ & \\
L vs. N slopec & 1 & 0.13117662 & 6.13 & 0.01 & \\
L vs. I slope & 1 & 0.29734796 & 13.90 & $<0.01$ & \\
N vs. I slope & 1 & 0.06747469 & 3.15 & 0.08 & \\
\hline
\end{tabular}

${ }^{a}$ Estimates for linear and quadratic slopes in the respective regression equations.

${ }^{\mathrm{b}}$ Full model regression includes both linear and quadratic terms.

${ }^{\mathrm{c}}$ Both linear and quadratic slopes.

Table 2. Estimates and contrasts of slopes for total number of viable teliospores in different plots over time

\begin{tabular}{|c|c|c|c|c|c|}
\hline Plot & $\begin{array}{c}\begin{array}{c}\text { Slope }^{\mathrm{a}} \\
\text { estimates }\end{array}\end{array}$ & $\begin{array}{l}\text { Standard } \\
\text { error }\end{array}$ & $t$ value & $P>|t|$ & $\begin{array}{c}\text { Full model } \\
R^{2}\end{array}$ \\
\hline \multicolumn{6}{|l|}{ Laboratory (L) } \\
\hline Linear & -105.0 & 40.6 & -2.59 & 0.01 & 0.82 \\
\hline Quadratic & 1.3 & 0.9 & 1.48 & 0.14 & \\
\hline \multicolumn{6}{|l|}{ Nonirrigated $(\mathrm{N})$} \\
\hline Linear & -201.9 & 25.8 & -7.82 & $<0.01$ & 0.55 \\
\hline Quadratic & 2.4 & 0.4 & 5.69 & $<0.01$ & \\
\hline \multicolumn{6}{|l|}{ Irrigated (I) } \\
\hline Linear & -239.8 & 25.7 & -9.32 & $<0.01$ & 0.68 \\
\hline Quadratic & 3.0 & 0.4 & 7.11 & $<0.01$ & \\
\hline Contrast & $\mathrm{df}$ & Contrast SS & $F$ value & $P>F$ & \\
\hline L vs. N slopes ${ }^{c}$ & 1 & 1977607 & 4.10 & 0.04 & \\
\hline L vs. I slopes & 1 & 3826050 & 7.94 & 0.01 & \\
\hline $\mathrm{N}$ vs. I slopes & 1 & 520217 & 1.08 & 0.30 & \\
\hline
\end{tabular}

${ }^{a}$ Estimates for linear and quadratic slopes in the respective regression equations.

${ }^{\mathrm{b}}$ Full model regression includes both linear and quadratic terms.

${ }^{\mathrm{c}}$ Both linear and quadratic slopes.
3 months after placing teliospores in the field. The reduction may have been caused by an increase in specific gravity of teliospores during weathering, perhaps the result of loss of the sheath surrounding the teliospores, allowing entry of water. An increase in specific gravity might cause teliospores to sink in the sucrose extraction solution and not be separated from the soil particles. It is also possible that the teliospores were not separated from the soil particles because soil particles and teliospores adhered to each other.

Enumeration of teliospores extracted from soil samples, and their germinability, provided useful information. However, using only these data one would greatly overestimate teliospore losses during the first year. Alternatively, using only germination percentages would have underestimated loss. Teliospores no longer present due to decomposition would have been ignored; these obviously would all have been nonviable if present. A determination of total number of viable teliospores provided a complete determination of the numbers of living teliospores in soil, regardless of whether or not they were extracted from the soil, and increased confidence in the final conclusions. Use of this technique in combination with the use of acidic electrolyzed water (3) will allow more confidence in determinations of effects of location, soil type, climate, and crop management on teliospore longevity. The ability to quantitate viable teliospores will be a powerful tool for making disease control decisions and may provide information as to where the disease can and cannot occur.

We found that soil depth had no significant effect on viability, and some teliospores survived at least 48 months in both irrigated and nonirrigated field plots (Figs. $1 \mathrm{~B}$ and 2). Because our data were both quantitative and accounted for all viable teliospores, it allowed analyses that determined rates of decrease in numbers of viable teliospores in the soil populations. Decrease in viability was not affected by temperature. Had temperature affected viability, we would have seen a difference in longevity at different soil depths. For example, there was no significant difference in longevity at $2 \mathrm{~cm}$ depth, where temperatures climbed to over $50^{\circ} \mathrm{C}$, and 20 $\mathrm{cm}$, where maximum temperatures never approached this level.

However, in a study conducted in Sonora, Mexico, where only intact teliospores from bags placed in soil were examined, Smilanick and coworkers (19) reported that teliospore germinability after 22 months persisted only among those buried $6 \mathrm{~cm}$ deep in dry soil, while the germinability of those on the soil surface or buried in moist, cropped soil had declined markedly.

Krishna and Singh (12) in India reported that $T$. indica teliospores in pots of soil 
were viable for 45 months at the soil surface, 39 months at 3 in, and 27 months at 6 in depth. Munjal (14), also working with teliospores in pots of soil in India, reported survival for 42 months at 3 in. The lengths of survival data in each of their studies were qualitative and based on whether or not viable teliospores were detected. The quantitative data of Rattan and Aujla (16) showed that in soil in earthen pots some teliospores survived for at least 27 months at 0 to $5 \mathrm{~cm}, 6$ to $15 \mathrm{~cm}$, or 16 to $20 \mathrm{~cm}$. Survival after 27 months, based on germination percentages of extracted teliospores, was significantly higher at 0 to $5 \mathrm{~cm}$ $(3.39 \%)$ than at 16 to $20 \mathrm{~cm}(1.00 \%)$ and was significantly higher in loamy sand than in clay and sandy loam soils.

In our study, regression analyses showed that both teliospore germination and total number of viable teliospores steadily declined over time (Figs. 1B and 2). However, regression analyses of total number of viable teliospores accounted for much more of the overall variation than did analyses of percentages of extracted teliospores that germinated (Tables 1 and 2). The quadratic regressions (Fig. 2) with total number of viable teliospores were more representative of typical survival of microorganisms in soil, i.e., relatively quick initial demise of large numbers of spores followed by a much slower demise of a smaller number of resilient spores (15). Based on total number of viable teliospores, there were no significant differences in teliospore survival between irrigated and nonirrigated plots, although there was a trend for teliospores to survive longer in the latter. This seems to indicate that soil moisture, per se, was not a primary factor influencing survival. Since total number of viable teliospores represented all viable teliospores of $T$. indica in the soil populations, we believe it was a better measure of the level of viability.

The fact that some of the teliospores were still viable after 48 months is not surprising. Disease reappears every few years in Arizona, indicating that either new inoculum is introduced with seed, or some inoculum survives in the soil from one "outbreak" to the next. We can hypothesize that if the numbers of viable teliospores were to drop below a certain threshold number required to initiate infection, disease would disappear. Results of longevity studies in India are valuable, but are only qualitative or were performed under highly unnatural conditions. Quantitative data from field studies, such as presented here, are much more useful and will provide a means with which to make critical disease control decisions. If and when the minimum number of teliospores required to incite disease is determined, its combined use with teliospore numbers expected to survive in soil will help determine the threat of establishment of Karnal bunt in new areas.
We describe changes in teliospore viability over time in soils in an area of the United States considered "somewhat conducive" to development of Karnal bunt.
Teliospore longevity, however, may vary in different soil types or regions of the country.

The research that we described examined the effects of time as a variable on

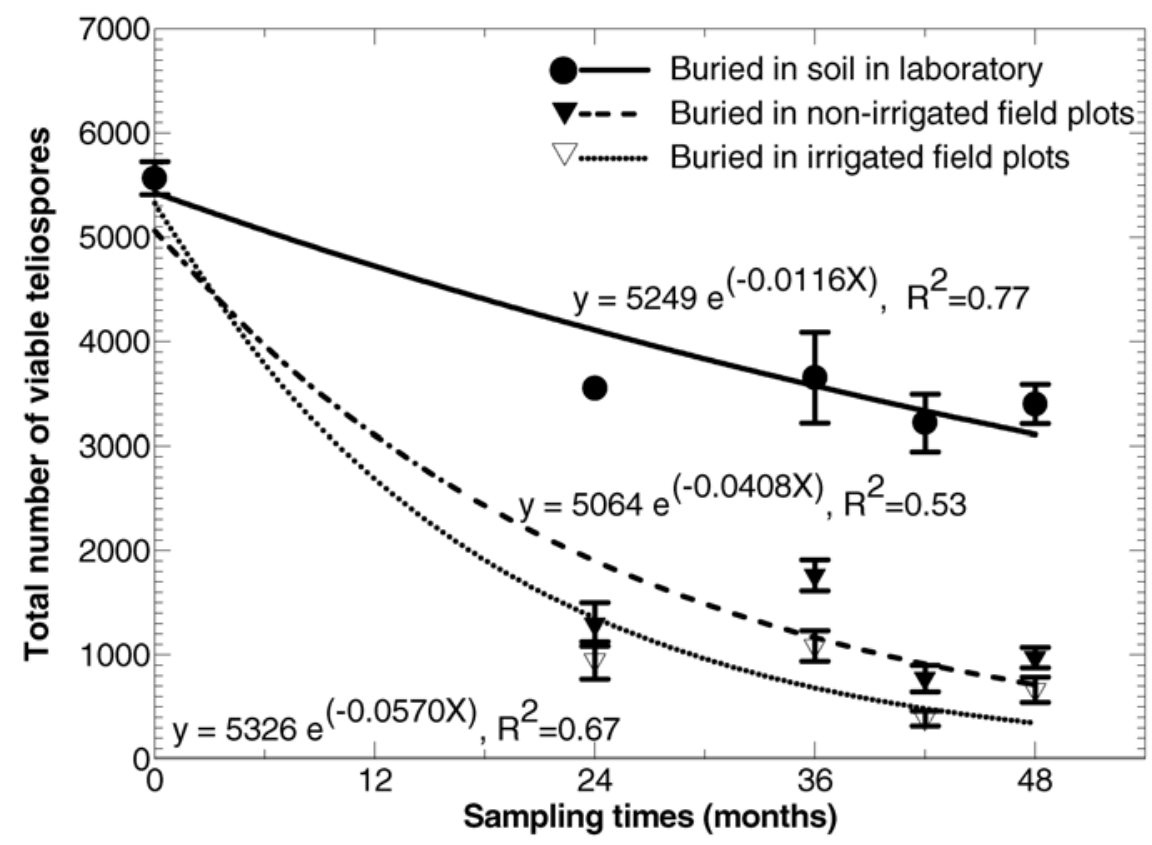

Fig. 2. Nonlinear regressions of total numbers of viable teliospores in irrigated and nonirrigated field plots and in soil in the laboratory over five sampling times. Linear transformations of the regression equations are: $\ln \left(y_{\text {laboratory }}\right)=8.60-0.0116 X ; \ln \left(y_{\text {nonirrigated }}\right)=8.53-0.0408 X ; \ln \left(y_{\text {irrigated }}\right)=8.58-$ $0.0570 X$. Standard errors of the means are indicated.

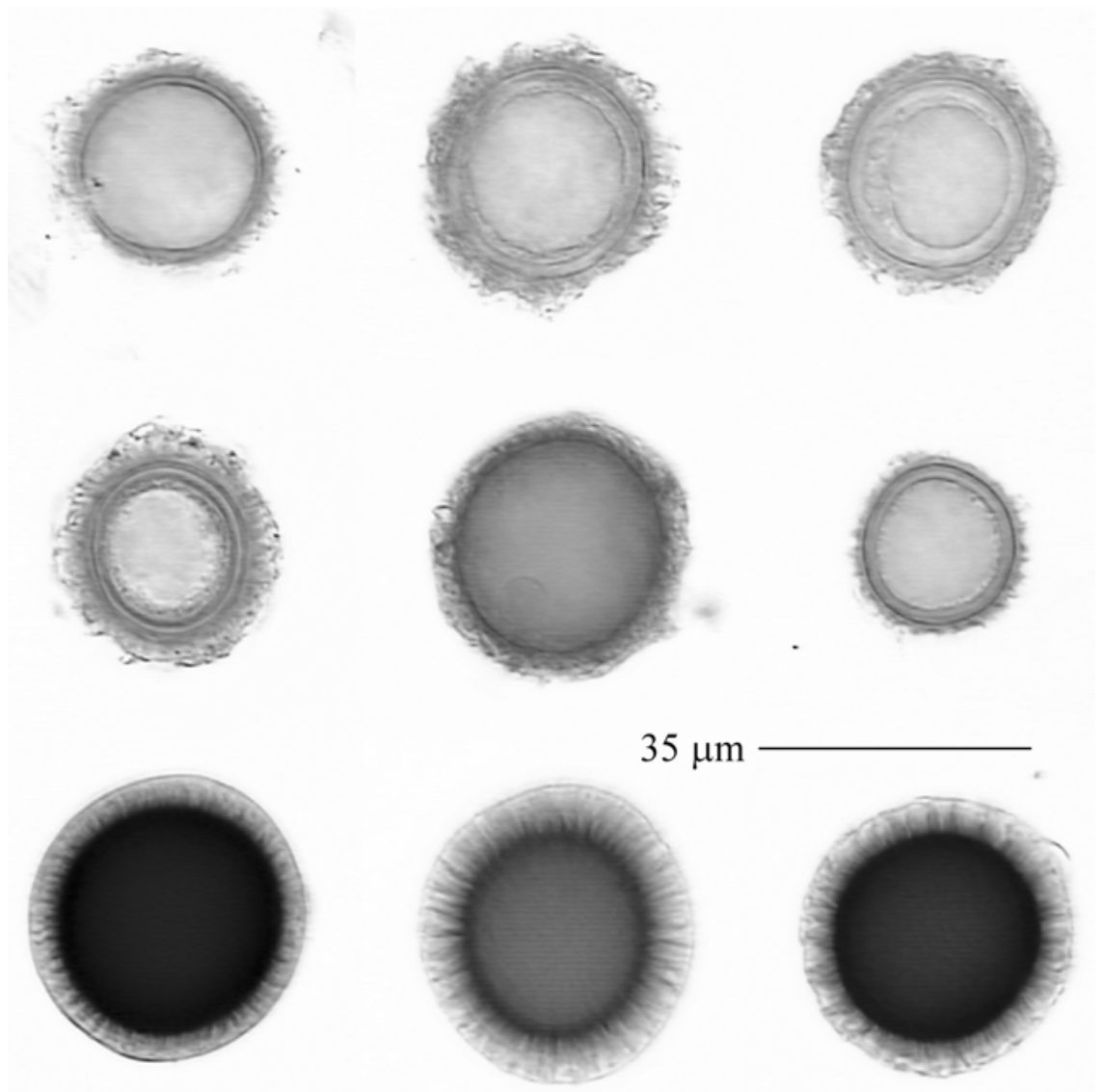

Fig. 3. Representative teliospores extracted from soil maintained for 48 months in nonirrigated field plots (top row), in irrigated field plots (middle row), or in the laboratory (bottom row). 
teliospore longevity. Other workers, including Dupler et al. (8), Smilanick et al. $(18,19)$, and Rattan and Aujla (17), examined the effects of environment on the teliospore germination process. The effects of short-term, 7- to 14-day exposure of teliospores to specific moisture and temperature conditions on teliospore germination may be of higher or lower importance than the much longer, but similar, exposures on longevity. For example, soil moisture may have a much greater effect on teliospore germination (8) than it does on teliospore longevity. It is important that the different parts of the life cycle be distinguished when considering effects of specific environmental parameters on disease.

Karnal bunt presently is of special interest because of its potential effect on international export of wheat. The preponderance of literature indicates that Karnal bunt is a minor disease that causes small reductions in yield and quality under favorable, but uncommon, conditions $(5,9)$. The disease likely has been present in India, Pakistan, and Afghanistan for at least 100 years (9). Throughout southern Asia, nomadic tribes have carried wheat across borders with no evidence of it becoming established in most places. Furthermore, within the last 40 years, wheat shipments from Karnal bunt endemic areas to nonendemic areas have occurred without known establishment of the disease (9). The disease is very limited in distribution and occurs sporadically and only in warm climates $(4,9)$. Direct disease losses almost never exceed a few tenths of a percent when data are collected for large areas $(4,5,9)$. This evidence suggests that environmental factors severely restrict spread and establishment of Karnal bunt. It is our goal to iden- tify these factors. Success requires development of methods and tools. The total number of viable teliospores method described in this paper will make it possible to accurately determine the ability of Karnal bunt teliospores to survive and become established in specific soils.

\section{ACKNOWLEDGMENTS}

We thank J. Smilanick and B. Goates for many helpful suggestions throughout the study; G. Fuentes-Davila for providing the teliospores from Sonora, Mexico; E. Alexander for providing the electrolysis apparatus for generating AEW and guidance in its use; and Megan Reeher and the late Lillian Zuback for their excellent technical assistance.

\section{LITERATURE CITED}

1. Babadoost, M., and Mathre, D. E. 1998. A method for extraction and enumeration of teliospores of Tilletia indica, T. controversa, and T. barclayana in soil. Plant Dis. 82:13571361.

2. Babadoost, M., Mathre, D. E., Johnston, R. H., and Bonde, M. R. 2004. Survival of teliospores of Tilletia indica in soil. Plant Dis. 88:56-62.

3. Bonde, M. R., Nester, S. E., Khayat, A., Smilanick, J. L., Frederick, R. D., and Schaad, N. W. 1999. Comparison of effects of acidic electrolyzed water and $\mathrm{NaOCl}$ on Tilletia indica teliospore germination. Plant Dis. 83:627-632.

4. Bonde, M. R., Peterson, G. L., Schaad, N. W., and Smilanick, J. L. 1997. Karnal bunt of wheat. Plant Dis. 81:1370-1377.

5. Butler, L. 1990. Karnal bunt, quarantine and the international shipment of CIMMYT wheat seed. Proc. Bien. Workshop Smut Fungi, 7th.

6. Carter, M. R., ed. 1993. Soil Sampling and Methods of Analysis. Canadian Society of Soil Science, Lewis Publishers, Boca Raton, FL. pp. 542-544.

7. Chib, H. S., Kalha, C. S., Gupta, B. R., Tikoo, M. L., and Gupta, R. S. 1990. Studies on the longevity of Neovossia indica - The incitant of Karnal bunt of wheat in soil. Plant Dis. Res. 5(Special): 17-18

8. Dupler, M., Smilanick, J. L., and Hoffmann, J. A. 1987. Effect of matric and osmotic potential on teliospore germination of Tilletia indica. Phytopathology 77:594-598.

9. Fuentes-Davila, G. 1998. Karnal bunt of wheat. Proc. Bunts Smuts Wheat; An International Symposium. August 17-20, 1997.

10. Goates, B. J. 1988. Histology of infection of wheat by Tilletia indica, the Karnal bunt pathogen. Phytopathology 78:1434-1441.

11. Graham, S. 1959. The effects of various reagents, mounting media, and dyes on the teliospore walls of Tilletia controversa. Mycologia 51:477-491.

12. Krishna, A., and Singh, R. V. 1983. Longevity of teliospores of Neovossia indica causing Karnal bunt of wheat. Indian J. Mycol. Plant Pathol. 13:97-98.

13. Mathur, S., and Cunfer, B. M. 1993. Karnal bunt. Pages 31-43 in: Seed-borne Diseases and Seed Health Testing of Wheat. Jordbrugsforlaget, Frederiksberg, Denmark.

14. Munjal, R. L. 1970. Studies on Karnal bunt of wheat. Ph.D. thesis. Punjab University, Chandigarh.

15. Park, D. 1965. Survival of microorganisms in soil. Pages 82-98 in: Ecology of SoilBorne Plant Pathogens. K. F. Baker and W. C. Snyder, eds. University of California, Berkeley.

16. Rattan, G. S., and Aujla, S. S. 1990. Survival of Karnal-bunt (Neovossia indica) teliospores in different types of soil at different depths. Indian J. Agric. Sci. 60:616-618.

17. Rattan, G. S., and Aujla, S. S. 1992. Ecology of germination of the teliospore of Karnal-bunt pathogen (Neovossia indica). Indian J. Agric. Sci. 62:228-231.

18. Smilanick, J. L., Hoffmann, J. A., and Royer, M. H. 1985. Effect of temperature, pH, light, and desiccation on teliospore germination of Tilletia indica. Phytopathology 75:1428-1431.

19. Smilanick, J. L., Prescott, J. M., Hoffmann, J. A., Secrest, L. R., and Weise, K. 1989. Environmental effects on survival and growth of secondary sporidia and teliospores of Tilletia indica. Crop Prot. 8:86-90.

20. Warham, E. J. 1986. Karnal bunt disease of wheat: A literature review. Trop. Pest Manage. 32:229-242.

21. White, G. C. 1992. The Handbook of Chlorination. Van Nostrand Reinhold, New York. 